\title{
Model of Strategy of Relative Stability and Flow for Kariba Dam
}

\author{
Xiaoyu Zhu \\ North China Electric Power University (Baoding), Baoding 071000, China \\ 1193341313@qq.com
}

Keywords: flood control, water and sediment regulation, system dynamics.

\begin{abstract}
If tourism benefits, plutonomy benefits and generated hydropower are incorporated in the mathematical model to be studied, it is bound to make the model very complex and difficult to solve. To solve this problem, the key role of dam system in flood control, water and sediment regulation should be considered, then the problems would be simplified, and the accuracy of the main project optimization planning could be ensured. At the same time, in order to overcome the limitations of nonlinear programming in the research of small and medium-sized dams ,the model of relative stability and flow strategy of new dam system is established based on the principle of system dynamics.
\end{abstract}

\section{Introduction}

The Kariba Dam is a double curvature concrete arch dam in the Kariba Gorge of the Zambezi River basin, which is built to generate hydropower basically. Institute of Risk Management of South Africa warned that the dam is in dire need of maintenance. The dam forms Lake Kariba which is one of the largest reservoirs in the world, holding 185 cubic kilometers of water.

There are lots of previous researches on managing Zambezi River, which can facilitate our comprehension of the problem.

For example, Ashok Swain and Patrik Stålgren researched existing circumstances of Zambezi River basin. The team of Philip H. Brown modeled the costs and benefits of dam construction from a multidisciplinary perspective.

But all these attemptions failed. So we need to bulid a more scientifical and available scheme to solve the problems above.

\section{Calculation of the basic characteristics of the dam}

(1)Dam height and storage capacity

$$
V=825 \times\left(\frac{H}{2}\right)^{2.535}
$$

(2)Dam height and area of sediment

$$
S=330 H^{2.55}
$$

(3)Dam height, crest length and earthwork volume of dam body

$$
W=1.37 H^{2.035} b^{0.838}
$$

\section{Calculation of spillway flood discharge and flood modulation}

\subsection{Calculation of cost of the spillway}

The flow through the spillway is the core of calculation of spillway project cost. It is necessary to consider the discharge flow of the upstream dam and the total discharge flow in a certain period in calculating the maximum flow of each dam spillway, and then use the Gaoqielin Formula to calculate the maximum flow of spillway of the dam. The cost of the spillway project can then be calculated from the regression equation between flow and engineering costs. [7] Calculation formula of spillway's maximum flow is an empirical formula:

$$
W_{y}=\left(2.422 Q^{0.4316}\right) L
$$


Where:

$W_{y}$ : Spillway works (or construction costs)

$Q$ : Maximum flow of spillway

$L$ : Length of spillway

\subsection{Calculation of flood modulation for dam system}

When the upstream dam is flooded, the downstream dam's spillway flow is calculated as follows:

$$
Q=\left(q_{p}+q_{u}\right)\left(1-\frac{V^{\prime \prime}}{W_{p}+W_{u}}\right)
$$

$q_{p}$ : Peak flow with frequency $\mathrm{p}$ in interval, can be found through historical data at the same period $\left(\mathrm{m}^{3} / \mathrm{s}\right)$

$q_{u}$ : Maximum flow of spillway of adjacent upstream dam $\left(\mathrm{m}^{3} / \mathrm{s}\right)$

$W_{p}$ : The total flood volume with frequency $\mathrm{p}$ in interval area $\left(10^{4} \mathrm{~m}^{3}\right)$

$W_{u}$ : Before calculating the maximum spillway discharge of the dam, the total flood discharge of the adjacent upstream dam spillways $\left(10^{4} \mathrm{~m}^{3}\right)$

$V$ ': The detention capacity of dam which is one of the decision variables of optimization planning $\left(10^{4} \mathrm{~m}^{3}\right)$

\section{Establishment of model of strategy of relative stability and flow}

Description of the objective function: Objective function of multi-objective optimization is designed for the purpose of minimizing cost-benefit and maximizing safety factor. It should be noted that, unlike the objective function of the "Dam Number Determination" model described above, only the calculations of spillway and peak shaving are carried out in the strategy model without account for the full cost. When the objective function reaches the minimum value, it means that the value of the corresponding decision variable is the best.

Objective function:

$$
\left\{\begin{array}{l}
\max I p=\frac{W p_{i}}{S\left(h+h_{c}\right)} \\
\min f\left(X_{i}\right)=\sum_{i=1}^{n}\left\{d_{v} \alpha_{i} X_{i}^{\beta_{i}}+d_{y i} \delta\left[\left(q_{p i}+q_{u i}\right)\left(1-\frac{X_{n+i}}{W_{p i}+W_{u i}}\right)\right]^{\varepsilon_{i}}\right. \\
\left.\times L_{y i}+d_{y q}\left(U_{i}+2 h_{k i}\right) L_{y i}\right\}-\sum_{i=1}^{n} T_{s} \beta R \psi_{i} X_{i}^{\varphi_{i}} \\
X_{i} \geq O \\
V_{i}-X_{i}-X_{n+i} \geq 0 \\
\frac{A_{i} W_{X_{i}}}{\gamma}-30 \geq 0
\end{array}\right.
$$

Where:

(1) $n$ - The number of dam sites

(2) $x_{i} \longrightarrow$ Decision variables, marking the mud storage capacity of the ith dam site, $\mathrm{i}=1,2, \ldots$, $\mathrm{n}$

(3) $x_{n+i} \longrightarrow$ Decision variables, marking flood storage capacity of the ith dam site, $\mathrm{i}=1,2, \ldots, \mathrm{n}$

(4) $d_{b}$ Unit price of earthwork volume of dam body

(5) $d y_{t}$ - Unit price of earthwork volume of spillway

(6) $d y_{q}-$ Unit price of unit of spillway

(7) $\alpha_{i}$ The $\mathrm{i}$-th dam according to the requirements of the dam volume engineering coefficient

(8) $\beta_{i}$ - The i-th dam according to the storage capacity for dam engineering quantity index

(9) $\delta_{i}$ The i-th dam calculates the coefficient of the spillway earthwork according to the spillway flow 
(10) $\varepsilon_{i}$ - The i-th dam calculates the index of spillway earthwork according to the spillway flow

(11) $\varphi_{i^{-----}}$The coefficient of the dam area required by the $\mathrm{i}$-th dam according to the silt storage

(12) $\psi_{i} \_$The $\mathrm{i}$-th dam is based on the index of dam area required by the silo

\section{Restrictions}

Non - negative constraints: The reservoir capacity of the dam cannot be negative, that is, $\mathrm{x} i \geq 0$, $(\mathrm{i}=1,2, \ldots, 2 \mathrm{n}), \mathrm{n}$ is the number of dam sites, the dam on each dam has a detention and detention capacity of flood detention capacity, so the type $i$ in the maximum value of $2 n$.

Terrain constraint: Topography limits the growth of dam height, the maximum dam height corresponding storage capacity is the maximum storage capacity of terrain constraints, so the actual storage capacity of the dam should be less than the maximum, that is, $V_{i}-x_{i}-x_{n+i} \geq 0, i=1,2, \ldots, n$.

Sedimentation time constraints: AiM xi $/ \gamma-30 \geq 0$.

\section{Conclusion}

We fully considered the three options of their own characteristics. We build different computational models for each option separately, and get their respective costs and benefits. In the detailed analysis of Option 3, we considered many factors and consulted the sufficient data. Accordingly, there is sufficient basis for the proposed model and the establishment of the dam system.

\section{References}

[1] Swain, Ashok, and P. Stålgren. Managing the Zambezi: The Need to Build Water Institutions. Environmental Security in Southern Africa. 2000.

[2] Brown, P. H, et al. "Modeling the costs and benefits of dam construction from a multidisciplinary perspective. " Journal of Environmental Management 90.90 Suppl 3(2009):S303.

[3] K Darbourn , Impact of the Failure of Kariba Dam. fr.allafrica.com

[4] Kingman, J. F. C. "On continuous time models in the theory of dams." Journal of the Australian Mathematical Society 3.4(1963):480-487.

[5] WC Study . Kariba Dam Zambia and Zimbabwe.

[6] REN Xi ,KANG Tian-ke . An Application of Multi-Criteria Analysis Method in Hydropower Project. Journal of Guizhou University 2013, 30(5):31-38

[7] XING Jia ,SUN Wei-guang .Research Based on Analytic Hierarchy Process of Construction Scheme Evaluation Model of River Basin Planning Urban Sewage Treatment Plant. Environmental Science and Technology. 2015, (4) 